\title{
Effects of Blending on the Melting and Crystallization of Polyethylene and Polypropylene under High Pressure
}

\author{
Chitoshi NAKAFUKU \\ Faculty of Education, Kochi University, Kochi 780, Japan
}

(Received March 3, 1983)

\begin{abstract}
The melting and crystallization behavior of polyethylene (PE) and polypropylene (PP) blends under high hydrostatic pressures up to $500 \mathrm{MPa}$ was studied by differential thermal analysis (DTA). These high pressure crystallized blends were also investigated at 1 atm by DTA, Xray diffraction, and electron microscopy. The melting temperature $T_{\mathrm{m}}$ of PE in the blend under high pressure was determined from the peak temperature of a DTA curve of melting. The $T_{\mathrm{m}}$ versus pressure curve for PE in the blend shifts to the high pressure side with decreasing PE content. In the DTA curve of melting at $1 \mathrm{~atm}$ for a blend crystallized under $450 \mathrm{MPa}$, an endothermic peak that could not be assigned to the melting of folded PE chain crystals (FCC) appeared on the low temperature side of the melting peak for extended chain crystals (ECC), indicating that small PE crystals different from FCC were formed in the molten PP during crystallization. The X-ray diffraction pattern of this blend showed that no eutectic crystallization occurs even in the isothermal crystallization under high pressure. Electron microscopic observations of the fracture surface of the high pressure crystallized blend showed a clear boundary between the PE and PP domains, suggesting that no interdiffusion of the two polymers occurs.

KEY WORDS Blend / Polyethylene / Polypropylene / Melting / Crystallization / High Pressure / DTA / X-Ray / Electron Microscopy /
\end{abstract}

Many investigations on polyethylene (PE) and polypropylene (PP) blends have been carried out to improve the low temperature toughness or impact strength of PP. ${ }^{1}$ Since it is fundamentally important to obtain information on the compatibility of polymer molecules in blends, many studies on the compatibility of PE and PP have also appeared. Some investigators ${ }^{2-4}$ made microscopic observations on the PE/PP boundary to see whether interdiffusion of the two polymers occurs to give an interphase layer.

Differential thermal analysis (DTA) and differential scanning calorimetry (DSC) were used to study thermal behavior of PE/PP blends. Some authors ${ }^{1-5}$ found in the DTA curve separate endothermic peaks corresponding to the melting of $\mathrm{PE}$ and PP.

The melting and crystallization of pure polymers under high pressure have been studied by many investigators. ${ }^{6}$ In the case of PE, it is widely known that extended chain crystals (ECC) are formed under high pressures above $300 \mathrm{MPa}$. The existence of a high pressure hexagonal phase was confirmed in the past decade. ${ }^{7-9}$

For PP, melt-crystallization produces the triclinic $\gamma$ form under high pressure, ${ }^{10-12}$ and the monoclinic $\alpha$ form at $1 \mathrm{~atm}$.

The pressure dependence of the cloud point in blend polymer systems has been studied recently ${ }^{13,14}$ mainly in regard to the compatibility of amorphous and crystalline polymers or amorphous and amorphous polymers.

In this paper, the melting and crystallization of $\mathrm{PE}$ and $\mathrm{PP}$ in their blends under high pressure are reported. It is shown that the behavior of PE in the blend is different from that in the pure state. High pressure DTA measurements were performed on PE/PP blends of different composition. The boundary of the $\mathrm{PE} / \mathrm{PP}$ phases in a sample was observed using an electron microscope. X-Ray diffraction measurements were performed on the same sample. 


\section{EXPERIMENTAL}

The samples used in this study were commercial grade high density PE, Hizex $2200 \mathrm{~J}$, with a viscosity-average molecular weight $M_{v}=40,000$, provided by Mitsui Petrochemical Industries Co. and isotactic PP, with a molecular weight $M_{v}=$ 420,000, supplied by Mitsubishi Yuka Co. Mixed $\mathrm{PE}$ and PP pellets were dissolved in $p$-xylene at $135^{\circ} \mathrm{C}$ to make a solution with a concentration of $0.1 \%$. Following slow cooling to room temperature at a rate of $1^{\circ} \mathrm{C} \mathrm{min}^{-1}$, the precipitated crystals were filtered and dried in a vacuum oven. The composition ratio ( $\mathrm{PE} / \mathrm{PP})$ was changed from $80 / 20$ to $5 / 95$.

High pressure DTA measurement was performed using the apparatus reported elsewhere. ${ }^{12}$ The heating rate was $6^{\circ} \mathrm{C} \mathrm{min}^{-1}$ and the cooling rate, $5^{\circ} \mathrm{C}$ $\min ^{-1}$ for all DTA measurements.

A sample for electron microscopy was prepared by the following procedure. A block of the blend obtained by filtration was covered by epoxy resin and placed in the DTA cell to crystallize from the melt under high pressure. The temperature of the sample was monitored by the DTA thermocouple. The sample crystallized under high pressure was cleaved in liquid nitrogen and was examined under an electron microscope using the two-stage standard replication technique with cellulose acetate and chromium metal. A Hitachi HS-7 electron microscope was used. X-Ray diffraction photographs were taken on a cylindrical camera with radiation of $\mathrm{Ni}$ filtered $\mathrm{Cu} K \alpha$ for $1 \mathrm{~h}$.

\section{RESULTS AND DISCUSSION}

\section{Effects of Blending on the High Pressure Phase of PE}

The DTA curve of pure PE under high pressure shows complicated features, because the orthorhombic to hexagonal phase transition occurs below the melting temperature at pressures above about $350 \mathrm{MPa}$. Figure 1 shows the high pressure DTA curves of pure PE and the blend of $40 / 60$ in PE/PP. The DTA melting curve at $1 \mathrm{~atm}$ on the blend sample crystallized at $1 \mathrm{~atm}$ (curve d) shows two endothermic peaks corresponding to the melting of the FCC of PE at $132^{\circ} \mathrm{C}$ and the melting of the $\alpha$ form crystal of $P P$ at $165^{\circ} \mathrm{C}$. In the DTA curve of melting above $350 \mathrm{MPa}$ of pure $\mathrm{PE}$ crystallized at $1 \mathrm{~atm}$, three endothermic peaks and one exothermic

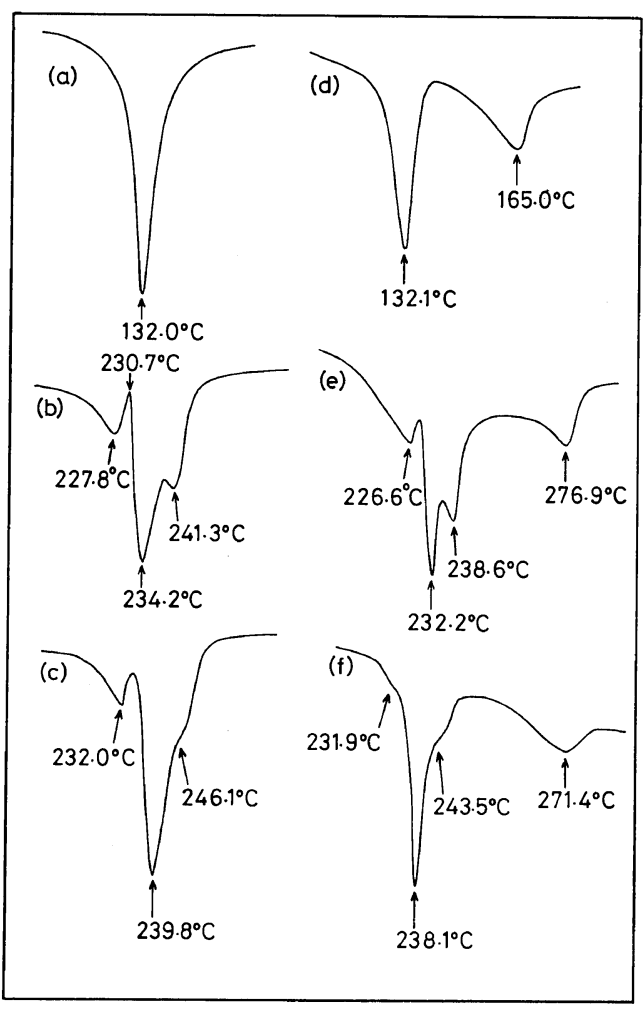

Figure 1. DTA curves of melting for pure PE and PE/PP blend of (40/60): (a), 1 atm DTA of PE meltcrystallized at $1 \mathrm{~atm}$; (b), $458 \mathrm{MPa}$ DTA of PE meltcrystallized at $1 \mathrm{~atm}$; (c), $484 \mathrm{MPa}$ DTA of PE meltcrystallized at $450 \mathrm{MPa}$; (d), $1 \mathrm{~atm}$ DTA of the blend melt-crystallized at $1 \mathrm{~atm}$; (e), $450 \mathrm{MPa}$ DTA of the blend melt-crystallized at $450 \mathrm{MPa}$; (f), $477 \mathrm{MPa}$ DTA of the blend melt-crystallized at $450 \mathrm{MPa}$.

peak appear as shown in curve b. These peaks of pure $\mathrm{PE}$ under high pressure were assigned as follows. ${ }^{15,16}$ The $227.8^{\circ} \mathrm{C}$ peak is due to melting of FCC, the $230.7^{\circ} \mathrm{C}$ peak to recrystallization of the FCC melt, the $234.2^{\circ} \mathrm{C}$ peak to the transition from the orthorhombic to hexagonal phase, and the $241.3^{\circ} \mathrm{C}$ peak to melting of the high pressure hexagonal phase. The high pressure DTA curve of pure PE crystallized under high pressure (curve c) is somewhat different in shape from that of the sample crystallized at $1 \mathrm{~atm}$. The peak and shoulder temperatures in curve c, $239.8^{\circ} \mathrm{C}$ and $246.1^{\circ} \mathrm{C}$, agree with $T_{\mathrm{tr}}$ (ortho-hexa transition temperature) and $T_{\mathrm{m}}$ (melting temperature of the hexagonal phase), as determined by Bassett and Turner ${ }^{7}$ and Yasuniwa et $a l{ }^{15}$ within experimental error. However, the peak 


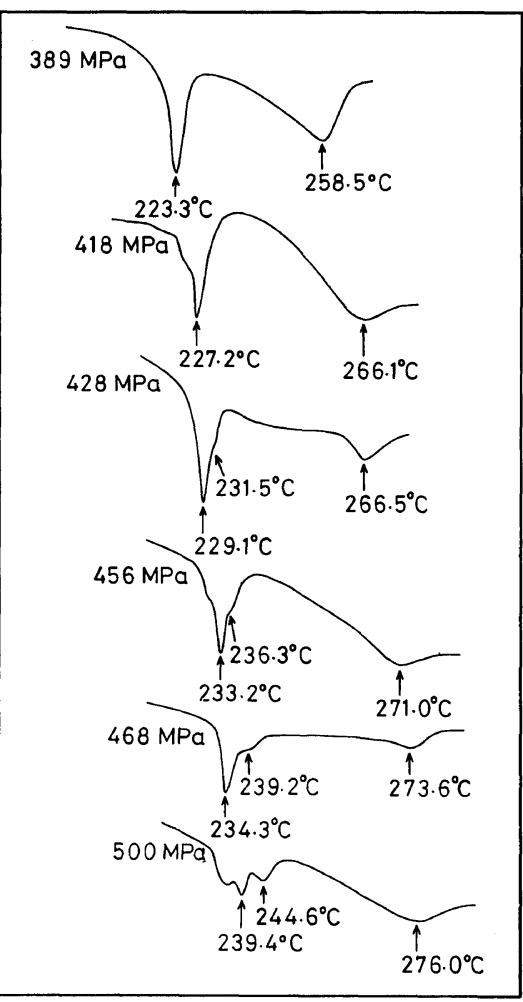

Figure 2. DTA curve of melting under high pressure for the blend $(20 / 80)$ crystallized at $460 \mathrm{MPa}$.

temperature in curve $\mathrm{b}$ for the $\mathrm{FCC}$ sample is $234.2^{\circ} \mathrm{C}$, which is about $2^{\circ} \mathrm{C}$ lower than the transition temperature $T_{\mathrm{tr}}$ at $458 \mathrm{MPa}$ determined by these two groups. Therefore, an ECC sample was used to determine the phase diagram of PE.

The $450 \mathrm{MPa}$ DTA curve for the blend sample crystallized at $1 \mathrm{~atm}$ shows three endothermic peaks around $230^{\circ} \mathrm{C}$ due to the transition and melting of PE and an endothermic peak of melting of the $\alpha$ form of PP at $276.9^{\circ} \mathrm{C}$. The DTA curve of the blend sample crystallized under high pressure resembles that of pure PE crystallized under high pressure in the melting region of $\mathrm{PE}$. The phase diagram of PE in the blend was also determined from the DTA curve for a high presssure crystallized sample, i.e., for the ECC of PE in the blend.

The degree of depression of $T_{\mathrm{tr}}$ and $T_{\mathrm{m}}$ under high pressure increases with decreasing PE content. Figure 2 shows the change in the DTA curve for the sample of 20/80 in PE/PP crystallized under high pressure with the change in pressure. A small shoulder corresponding to the melting of the hexa-

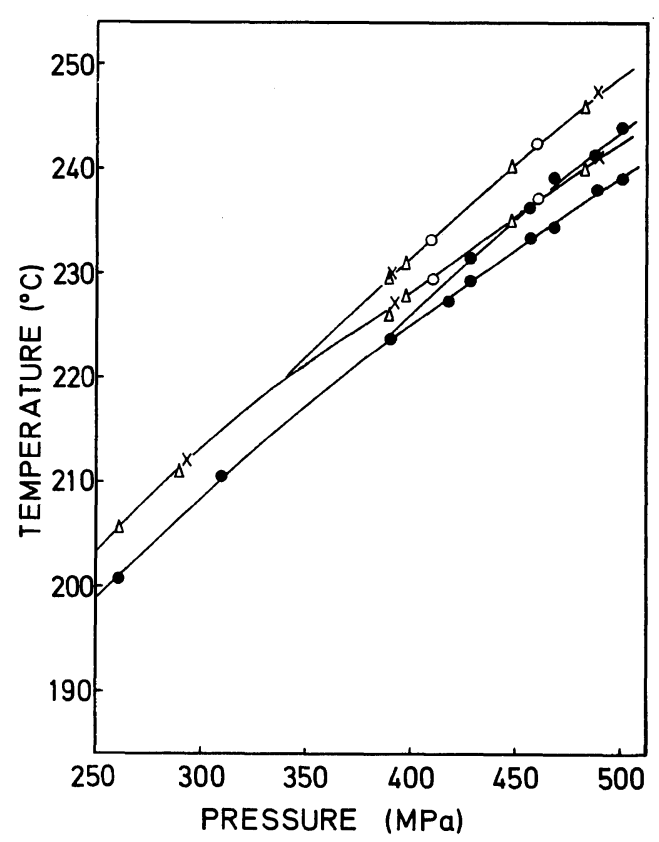

Figure 3. Phase diagram of pure $P E$ and $P E$ in the blend $(20 / 80)$ at high pressure: $\bigcirc$, Yasuniwa et al. ${ }^{15} ; \times$, Bassett $^{8} ; \triangle$, this work; $\bigcirc, \mathrm{PE}$ in the blend.

gonal phase appears on the high temperature side of the main peak above $428 \mathrm{MPa}$. In pure PE, the shoulder appears at $390 \mathrm{MPa}$. The temperature of the shoulder is plotted in Figure 3. The endothermic peak at $266.5^{\circ} \mathrm{C}$ is due to the melting of the $\gamma$ form crystal of PP. Figure 3 shows the phase diagrams of $\mathrm{PE}$ above $250 \mathrm{MPa}$ in the PE/PP (20/80) blend and pure PE. In this study, $T_{\mathrm{m}}$ of the ECC of pure $\mathrm{PE}$ at $1 \mathrm{~atm}$ was $140.8^{\circ} \mathrm{C}$ and $T_{\mathrm{m}}$ of the ECC of PE in the blend $(20 / 80)$ at $1 \mathrm{~atm}$ was $140.2^{\circ} \mathrm{C}$. The difference in $T_{\mathrm{m}}$ of ECC between pure PE and the blend PE increases with pressure, amounting to about $5^{\circ} \mathrm{C}$ at $300 \mathrm{MPa}$. The $T_{\mathrm{m}}$ versus pressure curve for the ECC of $\mathrm{PE}$ in the blend was formulated using the method of Wunderlich ${ }^{9}$ to obtain

$$
T_{\mathrm{m}}=A+B P-C P^{2}
$$

where $\mathrm{P}$ is the pressure in $\mathrm{MPa}$ and $T_{\mathrm{m}}$, the melting temperature of the orthorhombic crystal. The coefficients were evaluated by the least squares method for all blends and are listed in Table I.

The triple point in the phase diagram shifts to the high pressure side with decreasing PE content in the blend, i.e., from $350 \mathrm{MPa}$ for pure $\mathrm{PE}$ to about $400 \mathrm{MPa}$ for the composition 20/80. Table II lists 


\section{NAKAFUKU}

Table I. $A, B$, and $C$ coefficient values in eq 1

\begin{tabular}{|c|c|c|c|}
\hline \multirow{2}{*}{$\mathrm{PE} / \mathrm{PP}$} & $A$ & $B$ & $C$ \\
\hline & ${ }^{\circ} \mathrm{C}$ & ${ }^{\circ} \mathrm{CMPa}^{-1}$ & ${ }^{\circ} \mathrm{CMPa}^{-2}$ \\
\hline $100 / 0$ & 140.7 & 0.30 & $1.94 \times 10^{-4}$ \\
\hline $80 / 20$ & 140.7 & 0.29 & $1.85 \times 10^{-4}$ \\
\hline $60 / 40$ & 140.6 & 0.29 & $1.79 \times 10^{-4}$ \\
\hline $40 / 60$ & 140.3 & 0.29 & $1.74 \times 10^{-4}$ \\
\hline $20 / 80$ & 140.2 & 0.27 & $1.43 \times 10^{-4}$ \\
\hline
\end{tabular}

Table II. $T_{\mathrm{m}}$ and $T_{\mathrm{tr}}$ under high pressure for various composition in PE/PP blend

\begin{tabular}{|c|c|c|c|c|c|}
\hline \multirow{2}{*}{$\mathrm{PE} / \mathrm{PP}$} & \multirow{2}{*}{$\frac{1 \mathrm{~atm}}{T_{\mathrm{m}} /{ }^{\circ} \mathrm{C}}$} & \multirow{2}{*}{$\frac{150 \mathrm{MPa}}{T_{\mathrm{m}} /{ }^{\circ} \mathrm{C}}$} & \multirow{2}{*}{$\frac{300 \mathrm{MPa}}{T_{\mathrm{m}} /{ }^{\circ} \mathrm{C}}$} & \multicolumn{2}{|c|}{$450 \mathrm{MPa}$} \\
\hline & & & & $T_{\mathrm{tr}}{ }^{\circ} \mathrm{C}$ & $T_{\mathrm{m}} /{ }^{\circ} \mathrm{C}$ \\
\hline $100 / 0$ & 140.8 & 181.1 & 212.7 & 235.6 & 240.4 \\
\hline $80 / 20$ & 140.8 & 180.6 & 212.1 & 235.3 & 239.6 \\
\hline $60 / 40$ & 140.6 & 180.0 & 211.5 & 234.8 & 239.0 \\
\hline $40 / 60$ & 140.3 & 179.5 & 210.8 & 234.4 & 238.5 \\
\hline $20 / 80$ & 140.2 & 177.4 & 208.1 & 232.5 & 235.0 \\
\hline
\end{tabular}

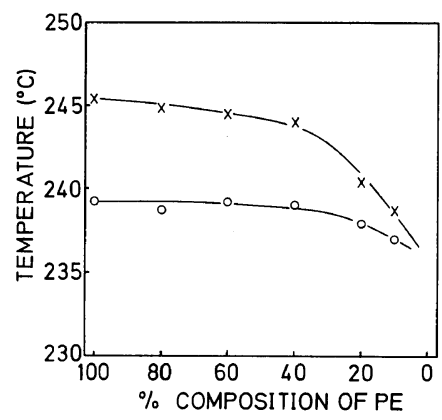

Figure 4. Composition dependence of $T_{\mathrm{m}}$ and $T_{\mathrm{tr}}$ of $\mathrm{PE}$ in the blend at $480 \mathrm{MPa}: O, T_{\mathrm{tr}} ; \times, T_{\mathrm{m}}$ of the hexagonal phase.

the values of $T_{\mathrm{m}}$ and $T_{\mathrm{tr}}$ in the blend at various pressures. Tables I and II show that the shift of $T_{\mathrm{m}}$ is remarkable at low content of PE. Figure 4 shows the changes in $T_{\mathrm{tr}}$ and $T_{\mathrm{m}}$ with change in composition in the blend at $480 \mathrm{MPa}$. The reduction in $T_{\mathrm{tr}}$ and $T_{\mathrm{m}}$ is remarkable at 20/80 in PE/PP. The shift of the triple point in the phase diagram for $\mathrm{PE}$ to the low pressure side has been reported by Oyama et al. ${ }^{17}$ on $\gamma$-ray irradiated pure PE. Shifting in the blend, occurs in the opposite direction.
Two different origins may be considered for the shifting of the triple point in the case of blend PE. One is the effect of blending with PP. Some compatibility effects on the boundary of two polymer crystals have been reported. Kryszewski et al. ${ }^{4}$ considered the possibility of the interdiffusion of $\mathrm{PE}$ and PP molecules at the boundary of the two polymers in the melt. Lovinger and Williams ${ }^{8}$ found a maximum in the tensile modulus versus $\mathrm{PE} / \mathrm{PP}$ composition curve at about $20 \%$ of $\mathrm{PE}$ in the blend, and ascribed this mechanical behavior to a reduction in spherulite size and an increase in the concentration of intercrystalline links.

The other cause for the shift of $T_{\mathrm{m}}, T_{\mathrm{tr}}$ and the triple point to the high pressure side may possibly be that the crystal size of the ECC of PE becomes smaller with decreasing PE content. The X-ray diffraction pattern taken at $1 \mathrm{~atm}$ on a high pressure crystallized blend showed a mixture of diffraction lines from PE and the $\gamma$-form crystal of PP. The intensity changed linearly with change in content of the constituent polymers. No such lines suggestive of alloy crystals of PE/PP as observed in annealed IPB-1 (isotactic polybutene-1)/PP blend ${ }^{19}$ were observed. The electron micrograph showed a clear boundary at the interface- of two polymers, as shown below. The shift of $T_{\mathrm{m}}$ and $T_{\mathrm{tr}}$ of PE in the blend may occur as a result of the size effect of PE crystals in the PP matrix. Confirmation of the above results will require additional research on $\mathrm{PE}$ blended with different crystalline polymers under high pressure.

The $T_{\mathrm{m}}$ of PP in the blend was measured under high pressure, but no notable difference was observed.

\section{High Pressure Crystallization of PE/PP Blend}

The pressure dependence of the crystallization temperatures $T_{\mathrm{c}}$ of pure PE and PP was determined independently by high pressure DTA. ${ }^{12,15} T_{\mathrm{c}}$ increased with pressure for both PE and PP, but the curvature of $T_{\mathrm{c}}$ versus pressure was different. The two curves crossed at $250 \mathrm{MPa}$. At $1 \mathrm{~atm}, T_{\mathrm{c}}$ of PP was higher than that of PE, but above $250 \mathrm{MPa}, T_{\mathrm{c}}$ of PE was higher than that of PP. In the cooling process, the DTA curve of the blend showed two exothermic peaks and the peak temperatures corresponded to the crystallization temperatures of pure PE and PP. Therefore, it was concluded that PE crystallizes in the PP melt above $250 \mathrm{MPa}$ and 


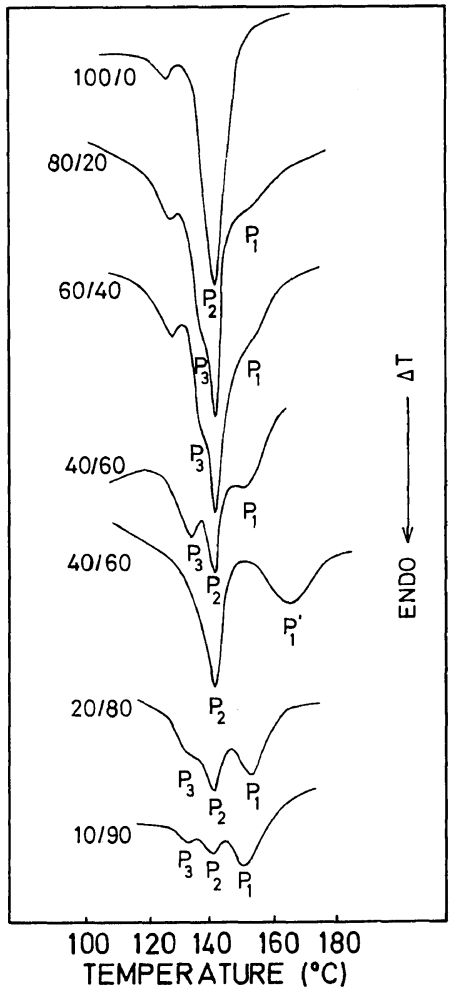

Figure 5. DTA curves of melting at $1 \mathrm{~atm}$ for pure PE and blends of different composition crystallized at $450 \mathrm{MPa}$. Composition is indicated in the figure. $P_{1}$ and $\mathrm{P}_{1}{ }^{\prime}$ are the melting peaks of PP $\gamma$-form crystal and $\alpha$ form crystal, respectively. $P_{2}$ peak is due to melting of ECC of PE. The lower curve for $40 / 60$ was obtained on the sample prepared by crystallizing only $P E$ and not melting PP crystal under high pressure. The other curves were obtained on the sample crystallized by cooling from a temperature above $T_{\mathrm{m}}$ of PP.

crystallizes in the solid PP below this pressure.

High pressure crystallized PE/PP blends of different composition were investigated at $1 \mathrm{~atm}$ by DTA, electron microscopy, and X-ray diffraction. Figure 5 shows a series of DTA curves at $1 \mathrm{~atm}$ for these blends crystallized from the melt at $450 \mathrm{MPa}$. The $\mathrm{P}_{1}$ peak at $151^{\circ} \mathrm{C}$ and the $\mathrm{P}_{1}{ }^{\prime}$ peak at $165^{\circ} \mathrm{C}$ correspond to the $T_{\mathrm{m}}$ of the $\gamma$-form and $\alpha$ form crystals of pure PP at $1 \mathrm{~atm}$, respectively. In the DTA curve of pure PE, a sharp endothermic peak corresponding to the melting of ECC was observed at $140.7^{\circ} \mathrm{C}\left(\mathrm{P}_{2}\right.$ peak $)$ and a small peak corresponding to the melting of the FCC of PE at $132^{\circ} \mathrm{C}$. The change in peak temperature with com- position was only $0.6^{\circ} \mathrm{C}$, from $140.7^{\circ} \mathrm{C}$ for $100 / 0$ to $140.1^{\circ} \mathrm{C}$ for $10 / 90$ in PE/PP. In the blend crystallized under high pressure, a shoulder $\left(\mathrm{P}_{3}\right.$ peak $)$ appeared on the low temperature side of the $\mathrm{P}_{2}$ peak. The temperature of the $\mathrm{P}_{3}$ peak decreased with decreasing $\mathrm{PE}$ content, from $139.1^{\circ} \mathrm{C}$ for $80 / 20$ to $134.1^{\circ} \mathrm{C}$ for $10 / 90$. In the sample crystallized at $1 \mathrm{~atm}$, the $\mathrm{P}_{3}$ peak did not appear at $1 \mathrm{~atm}$, as already shown by curve $d$ in Figure 1 . To see the difference in melting behavior at $1 \mathrm{~atm}$ between $\mathrm{PE}$ crystallized in the molten PP and the solid PP under high pressure, melt-crystallization of only $\mathrm{PE}$ in the blend was performed at $460 \mathrm{MPa}$ by cooling the sample from a temperature just above $T_{\mathrm{m}}$ of PE $\left(242.3^{\circ} \mathrm{C}\right)$ to a temperature below $T_{\mathrm{m}}$ of PP. In this process, $\mathrm{PP}$ in the blend did not melt. The $T_{\mathrm{m}}$ of PE in this sample was $140.6^{\circ} \mathrm{C}$, so that $\mathrm{ECC}$ of $\mathrm{PE}$ was formed in the solid PP by crystallization from the melt under high pressure. Taking this into account, we may conclude that the $\mathrm{P}_{3}$ peak is associated with the melting of PE crystals formed near the boundary of the two polymers. These PE crystals may be formed in the molten PP. During the crystallization of PE, molten PP molecules are considered to interfere with crystallization to the ECC form. As the PE content decreases, the interference effect may become stronger and the thickness of the crystals may decrease, leading to a depression of $T_{\mathrm{m}}$. The fact that the $\mathrm{P}_{3}$ peak height decreases by isothermal crystallization at $T_{\mathrm{c}}$ of PE under high pressure supports the above argument.

Electron microscopic observations were performed on the fracture surface of blends crystallized from melt under high pressure. Figure 6(a) shows the fracture surface of the blend (5/95) crystallized at $440 \mathrm{MPa}$. A stacking of long thin bands of ECC can be seen. Usually, small blocks of aggregated ECC of PE were observed to disperse in the PP matrix of the blend containing a small amount of PE. The average width of the band was about $3,000 \AA$. An isolated single crystal of ECC was seldomly observed even at a small content of PE $(5 \%)$. On the fracture surface of the high pressure crystallized blend of (10/90), a PE block consisting of ECC was also observed. Figure 6(b) shows the fracture surface of the blend $(20 / 80)$ crystallized under high pressure. A flat portion with a globular area of PP and a band of the ECC of PE can be seen. The globular area in high pressure crystallized pure PP has been reported by Sauer and Pae. ${ }^{21}$ The 


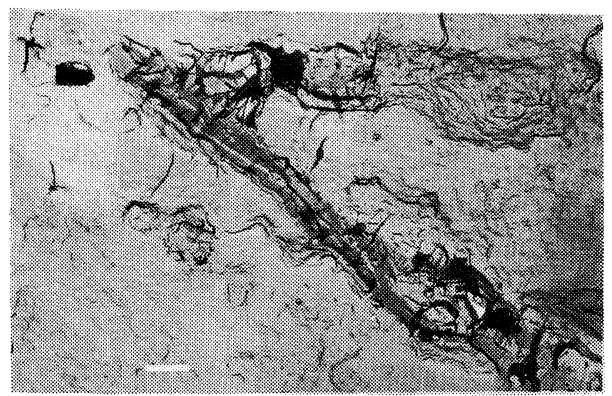

(a)

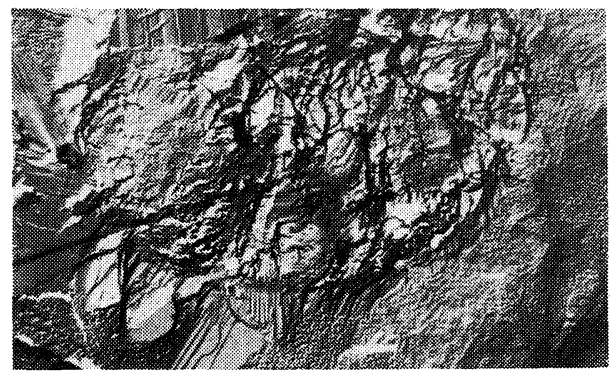

(b)

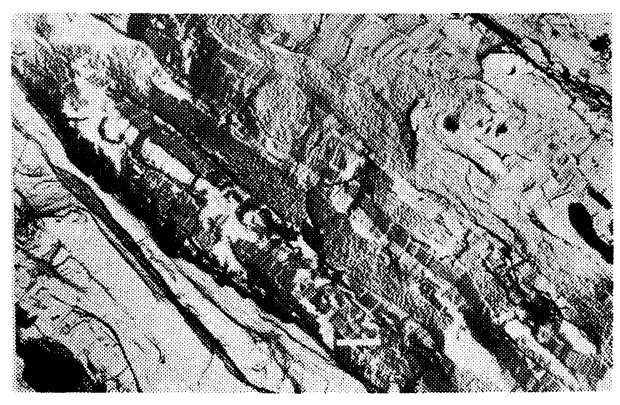

(c)

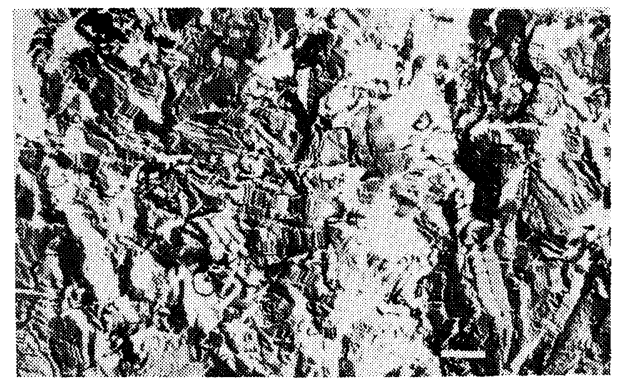

(d)

Figure 6. Electron micrograph of the fracture surface of high pressure crystallized blend. Scale bar means $1 \mu \mathrm{m}$ : (a), 5/95; (b), 20/80; (c), 60/40; (d), 80/20.

flat area is characteristic of the band of PE/PP crystallized from melt under high pressure, and corresponds to the crystal which shows an endothermic shoulder $\left(\mathrm{P}_{3}\right.$ peak $)$ in the DTA curve at $1 \mathrm{~atm}$ shown in Figure 5. In the blend of $(60 / 40)$, a sandwichlike pattern consisting of the band of ECC of PE and the globular area of PP appeared as shown in Figure 6(c). The average width of the PE band was about $0.5-1 \mu \mathrm{m}$, but a band thicker than $1 \mu \mathrm{m}$ was also observed. The block of ECC of PE increased with increasing PE content. The boundary of the PE band and the globular PP was clear, and no interdiffusion of these two molecules likely. Figure 6(d) shows the fracture surface of the blend $(80 / 20)$ crystallized under high pressure. In this sample, a small area of globular PP was dispersed between ECC of PE. These electron microscopic observations may be summarized as follows. ECC of $\mathrm{PE}$ is formed on melt-crystallization of $\mathrm{PE} / \mathrm{PP}$ blends under high pressure even at a PE content as small as $5 \%$, irrespective of whether PP is molten or solid. The size of the block of ECC of PE increases with increasing PE content in the blend.
This is also the case with the width of the band.

Acknowledgment. The author wishes to thank Professor T. Takemura of Kyushu University for permitting use of the electron microscope.

\section{REFERENCES}

1. A. P. Plochoski, "Polymer Blends," Vol. 2, D. R. Paul and S. Newman, Ed., Academic Press, New York, N. Y., 1978, pp 319-368.

2. J. Letz, J. Polym. Sci., A-2, 7, 1987 (1969).

3. J. Letz, J. Polym. Sci., A-2, 8, 1415 (1970).

4. M. Kryszewski, A. Galeski, T. Pakula, and J. Grebowicz, J. Colloid. Interface Sci., 44, 85 (1973).

5. D. A. Blackadder, Makromol. Chem., 182, 1271 (1981).

6. B. Wunderlich, "Macromolecular Physics," Vol. 1, Academic Press, New York, N. Y., 1973, Chapter III.

7. D. C. Bassett and B. Turner, Nature (London) Phys. Sci., 240, 146 (1972).

8. D. C. Bassett, "Developments in Crystalline Polymers-1," D. C. Bassett, Ed., Applied Science Publishers, London, 1982, pp 115-150. 
9. B. Wunderlich, "Macromolecular Physics," Vol. 3, Academic Press, New York, N. Y., 1980, Chapter VIII.

10. K. D. Pae, J. Polym. Sci., A-2, 6, 657 (1968).

11. D. R. Morrow, J. Macromol. Sci., Phys., B3, 53 (1969).

12. C. Nakafuku, Polymer, 22, 1963 (1981).

13. Y. Suzuki, Y. Miyamoto, H. Miyaji, and K. Asai, J. Polym. Sci., Polym. Lett. Ed., 20, 563 (1982).

14. N. Hiramatsu, S. Hashida, M. Yasuniwa, and S. Hirakawa, Polym. Prepr., Jpn., 31, 781 (1982).

15. M. Yasuniwa, C. Nakafuku, and T. Takemura,
Polym. J., 4, 526 (1973).

16. K. Matsushige and T. Takemura, J. Cryst. Growth, 48, 343 (1980).

17. T. Oyama, K. Takamizawa, Y. Urabe, and H. Hasegawa, Sōgōrikōgaku Kenkyuka Hōkoku, 1, 1 (1980).

18. A. J. Lovinger and M. L. Williams, J. Appl. Polym. Sci., 25, 1703 (1980).

19. R. M. Gohil and J. Petermann, J. Macromol. Sci., Phys. B., 18, 217 (1980).

20. J. A. Sauer and K. D. Pae, J. Appl. Phys., 39, 4959 (1968). 